\title{
Associated factors of willingness to undergo routine chlamydia trachomatis screening among hospital-based patients in Shenzhen, China: a cross-sectional study
}

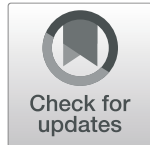

Rongxing Weng ${ }^{1}$, Fuchang Hong ${ }^{1}$, Chunlai Zhang ${ }^{1}$, Lizhang Wen ${ }^{1}$, Xiangsheng Chen ${ }^{2,3}$ and Yumao Cai ${ }^{1 *}$

\begin{abstract}
Background: Chlamydia trachomatis (CT) is a common sexually transmitted infection (STI) with significant morbidity. The study aimed to explore the willingness to undergo routine CT screening and its associated factors among hospital-based patients in Shenzhen.

Methods: We used data from the Shenzhen Gonorrhea and Chlamydia Intervention Programme. Participants were recruited with a stratified purposeful sampling design from 1 April 2018 to 16 May 2018. A structured questionnaire was used to obtain data on baseline characteristics and CT-related participant information.

Results: Of the 16,546 participants, $64.79 \%$ were women, with a mean age of $31.85 \pm 7.31$ of all participants. Of the participants, $88.78 \%$ were willing to undergo routine CT screening. According to multivariate logistic regression analyses, willingness to undergo routine $C T$ screening was associated with the following $(P<0.05)$ : being a woman $(A O R=1.53,95 \% C l=1.34-1.75)$, one year or more residency in Shenzhen $(A O R=1.64,95 \% C l=1.37-1.95)$, any secondary education $(A O R=2.46,95 \% C l=1.92-3.15)$, monthly income $\geq R M B 10,000(A O R=1.24,95 \% C l=1.01-$ 1.51), having forgotten $C T$ diagnosis history ( $A O R=1.42,95 \% \mathrm{Cl}=1.12-1.79$ ), without current STI-related symptoms $(\mathrm{AOR}=1.24,95 \% \mathrm{Cl}=1.10-1.41)$, and having correct understanding of the sequelae of $\mathrm{CT}$ infection $(\mathrm{AOR}=1.68,95 \%$ $\mathrm{Cl}=1.39-2.03)$.

Conclusion: This study reported high willingness to undergo routine CT screening among hospital-based patients in Shenzhen, and provided evidence for the promotion and the implementation of strategies and recommendations on routine CT screening in China.
\end{abstract}

Keywords: Chlamydia trachomatis, Routine screening, Willingness, Associated factors

\footnotetext{
* Correspondence: 64165469@qq.com

${ }^{1}$ Department of STD Control and Prevention, Shenzhen Center for Chronic Disease Control, No. 2021, Buxin Road, Luohu District, Shenzhen City 518020, Guangdong Province, China

Full list of author information is available at the end of the article
}

(c) The Author(s). 2020 Open Access This article is licensed under a Creative Commons Attribution 4.0 International License, which permits use, sharing, adaptation, distribution and reproduction in any medium or format, as long as you give appropriate credit to the original author(s) and the source, provide a link to the Creative Commons licence, and indicate if changes were made. The images or other third party material in this article are included in the article's Creative Commons licence, unless indicated otherwise in a credit line to the material. If material is not included in the article's Creative Commons licence and your intended use is not permitted by statutory regulation or exceeds the permitted use, you will need to obtain permission directly from the copyright holder. To view a copy of this licence, visit http://creativecommons.org/licenses/by/4.0/. The Creative Commons Public Domain Dedication waiver (http://creativecommons.org/publicdomain/zero/1.0/) applies to the data made available in this article, unless otherwise stated in a credit line to the data. 


\section{Background}

Chlamydia trachomatis (CT) is a common sexually transmitted infection (STI) with significant morbidity. According to the World Health Organization (WHO), the global estimate of new CT cases was 127.2 million in 2016 [1]. Untreated CT infection can cause several complications, such as pelvic inflammatory disease (PID), tubal infertility, ectopic pregnancy, and chronic pelvic pain in women [2,3]; and epididymitis, nongonococcal urethritis, and infertility in men $[4,5]$. About $85 \%$ of CT infections in women and men are asymptomatic, which indicates that CT screening is important in detecting these asymptomatic cases [6].

CT screening among young sexually active adults is recommended in many developed countries, including the USA, Denmark, Australia, the UK, Norway, and Sweden [7-9]. A nationwide scheme called the National Chlamydia Screening Programme (NCSP) was put forward in the UK [10], and all sexually active men and women aged under 25 years were targeted for annual chlamydia screening through various clinical and nonclinical settings. Similarly, the Shenzhen Gonorrhea and Chlamydia Intervention Programme (SGCIP), a pilot project of a national programme in China (the China Chlamydia Intervention Programme), was launched in 2017, and it was the first city-level CT screening programme in China [11]. However, there are no policy strategies for routine CT screening in China. Besides, adults aged 25 years or older should not be neglected in CT screening in China. A study in China reported a high prevalence $(9.09 \%)$ of CT infection among hospitalbased patients aged $>25$ years [11]. It is known that CT screening in the population with $\mathrm{CT}$ prevalence $>3 \%$ is cost-effective [12].

The CT screening programme is now an important part of the public health system. However, little is known about the acceptability of routine CT screening in the Chinese context, and it may be sensitive to undergo STI screening because of social stigma and invasive specimen collection [13]. Understanding which characteristics are associated with the willingness to undergo routine CT screening could inform health authorities in developing interventions and policy recommendations. This study, as part of the pilot project in China (SGCIP), aimed to explore the willingness to undergo routine CT screening, and to identify associated factors among hospital-based patients in Shenzhen.

\section{Methods}

\section{Setting and methods of participant selection}

We used data from a baseline study in the Shenzhen Gonorrhea and Chlamydia Intervention Programme. In this study, a stratified purposeful sampling design was used to identify study sites to include the study on the basis of the highest number of reported CT cases in 2017. Initially, we selected the administrative districts according to the number of reported CT cases. As hospitals in one district declined to participate in the study and the number of reported CT cases in three other districts was negligible, six of ten administrative districts in Shenzhen were included in the study. Second, the top four hospitals in each district for the number of reported CT cases were selected except for one district, with only two hospitals. A total of 22 hospitals were selected in this stage. Third, the top three departments for the number of reported CT cases in Shenzhen were identified (departments of obstetrics and gynecology, urology, and dermatology and venereology) and selected as the study sites in each hospital. From 1 April 2018 to 16 May 2018, the first 15 eligible patients per day in each department in the selected hospitals were asked to participate in a questionnaire interview after confirming the inclusion criteria of the participant and obtaining written informed consent. Inclusion criteria for participants comprised (1) age between 18 and 49 years, (2) having ever engaged in sexual intercourse, and (3) having had no antibiotic use in the last 2 weeks.

\section{Questionnaire survey \\ Main process}

Training about how to conduct the questionnaire interview according to the study protocols was provided for the investigation staff in each included hospital. After the inclusion criteria of the participant were confirmed, and informed consent was obtained, a structured questionnaire was used to obtain data on the baseline characteristics, CT knowledge, and screening willingness of the participants (details of the questionnaire given in Additional file 1).

\section{Baseline characteristics and CT-related participant information}

The following variables of baseline characteristics were gathered: gender, age, marital status, separation, type and length of residency, education level, health insurance, monthly income, and sexual orientation. Variables describing CT-related information were mainly on chlamydia testing and diagnosis history, STI-related symptoms, having a new sexual partner or multiple sex partners in the last 3 months, and CT screening willingness.

\section{Questions about willingness to undergo routine CT screening, chlamydia related-knowledge, and definition of Shenzhen Hukou and length of residency}

The question "are you willing to undergo routine CT screening once a year?" was intended to obtain the willingness to undergo routine CT screening from 
participants with two response options ("no" and "yes"). Two questions (Knowledge Q1 and Q2) were related to chlamydia infection knowledge, with 4 items in each question. For Knowledge Q1 "what do you know about genital Chlamydia trachoma infections?", four response options were provided: (a) "never heard of it", (b) "a kind of infectious disease", (c) "a kind of genital tract infection", and (d) "a kind of sexually transmitted disease". Response options were coded as follows: (a) "lack of understanding", and (b), (c), and (d) "Correct understanding", resulting in two knowledge levels. For Knowledge Q2 "what do you know about the dangers of genital chlamydia trachomatis infections on the human body?", four response options were provided: (a) "no dangers", (b) "may affect sexual life", (c) "may affect fertility", and (d) "know nothing about it". Response options were coded as follows: (a) or (d) "lack of understanding", and (b) or (c) "correct understanding", resulting in two levels of knowledge. Definition of the Shenzhen Hukou: Hukou system is a household registration system in China that is used to divide the Chinese population into agricultural and non-agricultural Hukou holders, which helps the government regulate population flows [14]. People with Shenzhen Hukou are those who have registered their permanent residence in Shenzhen. Length of residency is the length for which the participants have lived in the city of Shenzhen.

\section{Statistical analysis}

All data from the questionnaires were double entered into the computer using Epi Data software (Epi Data for Windows; The Epi Data Association Odense, Denmark) to establish a dataset. Mean \pm standard deviation (SD) was used to describe the distribution of continuous variables, and frequency (\%) was used to describe categorical variables. Crude odds ratios (OR) and their 95\% confidence interval $(\mathrm{CI})$ were calculated using univariate logistic regression analysis, and variables with $P<0.2$ were included in multivariate logistic regression analysis using a forward stepwise procedure to obtain adjusted odds ratios (AOR) and their 95\% CIs. Variance inflation factor (VIF) was calculated to assess the collinearity of independent variables, and an independent variable with VIF $>5$ was considered as highly collinear. We adopted a multivariate logistic regression model, defining screening willingness as a dependent variable, and gender, age, marital status, separation, Shenzhen $\mathrm{Hukou}$, length of residency, education, insurance, monthly income, sexual orientation, chlamydia testing and diagnosis history, STI-related symptoms, and Knowledge Q1 and Q2 as independent variables. All data analysis was performed on Statistical Package for Social Sciences (SPSS) version 21.0 software (SPSS Inc., Chicago, IL, USA). All tests were two-tailed, and $P<0.05$ was considered as statistically significant.

\section{Results}

Baseline and other participant characteristics

Baseline and other characteristics of participants are summarized in Table 1 . Of the participants, 723 who did not complete the question about willingness to undergo routine CT screening were excluded, leaving 16,546 participants (95.81\% of the participants) in final data analysis. Of the 16,546 participants, $64.79 \%$ were women, with a mean age of $31.85 \pm 7.31$ for all participants. Of the participants, $85.67 \%$ were older than 24 years old, and about three-quarters (73.73\%) were married. Around three-fourths (72.13\%) had not registered Shenzhen Hukou, and $87.93 \%$ had lived in Shenzhen 1 year or more. With regard to participant behaviors, only $8.79 \%$ had been tested for chlamydia infections, $6.27 \%$ had been diagnosed, and $38.02 \%$ had had a new sexual partner or multiple sex partners in the last 3 months.

\section{CT-related knowledge and screening willingness of participants}

CT-related knowledge and screening willingness of the participants are also shown in Table 1. Most participants $(88.78 \%)$ were willing to undergo routine CT screening. Around three-quarters of the participants lacked an understanding of chlamydia infections (Knowledge Q1 = 73.69\%; Q2 = 74.93\%).

\section{Factors associated with willingness to undergo routine CT screening}

In univariate analyses, 15 variables were associated with screening willingness at $P<0.20$ (Table 2). As shown in Table 3, the VIF value among all independent variables was lower than 5 , so no collinearity was detected. Results from the multivariate logistic regression model suggested that the following factors were significantly associated with screening willingness $(P<0.05)$ : being a woman $(\mathrm{AOR}=1.53,95 \% \mathrm{CI}=1.34-1.75), 1$ year or more residency in Shenzhen (AOR $=1.64,95 \% \mathrm{CI}=1.37-1.95)$, any secondary education $(\mathrm{AOR}=2.46,95 \% \mathrm{CI}=1.92-3.15)$, monthly income $\geq \mathrm{RMB} 10,000(\mathrm{AOR}=1.24,95 \% \mathrm{CI}=$ 1.01-1.51), having forgotten $\mathrm{CT}$ diagnosis history (AOR = 1.42, 95\% CI $=1.12-1.79)$, without current STI-related symptoms $(\mathrm{AOR}=1.24,95 \% \mathrm{CI}=1.10-1.41)$, and having correct understanding of the sequelae of $\mathrm{CT}$ infection $(\mathrm{AOR}=1.68,95 \% \mathrm{CI}=1.39-2.03)$.

\section{Discussion}

Rarely have studies reported on the screening willingness for chlamydia infections in China, and this is the first hospital-based and multisite survey to report a willingness to undergo routine CT screening in China. Our study indicated a high willingness in our study population $(88.8 \%)$, and that was reported in several previously conducted studies in China and other countries, having 
Table 1 Baseline characteristics, knowledge and screening willingness of participants

\begin{tabular}{|c|c|}
\hline Variables & Frequency (\%) ${ }^{\mathrm{a}}$ \\
\hline \multicolumn{2}{|l|}{ Gender $(n=16,513)$} \\
\hline Men & $5814(35.21 \%)$ \\
\hline Women & $10,699(64.79 \%)$ \\
\hline \multicolumn{2}{|l|}{ Age groups $(n=16,457)$} \\
\hline$\leq 24$ & $2359(14.33 \%)$ \\
\hline$>24$ & $14,098(85.67 \%)$ \\
\hline \multicolumn{2}{|l|}{ Marital status $(n=16,473)$} \\
\hline Single/Divorced/Widowed & $4327(26.27 \%)$ \\
\hline Married & $12,146(73.73 \%)$ \\
\hline \multicolumn{2}{|c|}{ Living separate and apart $(n=13,219)$} \\
\hline Yes & 1807 (13.67\%) \\
\hline No & $11,412(86.33 \%)$ \\
\hline \multicolumn{2}{|l|}{ Shenzhen Hukou $(n=16,248)$} \\
\hline No & $11,720(72.13 \%)$ \\
\hline Yes & $4528(27.87 \%)$ \\
\hline \multicolumn{2}{|l|}{ Length of residency $(n=16,325)$} \\
\hline$<1$ year & $1971(12.07 \%)$ \\
\hline$\geq 1$ year & $14,354(87.93 \%)$ \\
\hline \multicolumn{2}{|l|}{ Education level $(n=16,381)$} \\
\hline Primary school & $4692(28.64 \%)$ \\
\hline Any secondary & $11,689(71.36 \%)$ \\
\hline \multicolumn{2}{|c|}{ Monthly income (RMB) $(n=15,290)$} \\
\hline 0-4999 & $5361(35.06 \%)$ \\
\hline $5000-9999$ & $6942(45.40 \%)$ \\
\hline $10,000-$ & $2987(19.54 \%)$ \\
\hline \multicolumn{2}{|l|}{ Health insurance $(n=16,394)$} \\
\hline No & $5788(35.31 \%)$ \\
\hline Yes & $10,606(64.69 \%)$ \\
\hline \multicolumn{2}{|l|}{ Sexual orientation $(n=16,271)$} \\
\hline Homosexuality/bisexuality & $300(1.84 \%)$ \\
\hline Heterosexuality & $15,971(98.16 \%)$ \\
\hline \multicolumn{2}{|l|}{ Ever CT tested $(n=16,229)$} \\
\hline No & $14,803(91.21 \%)$ \\
\hline Yes & $1426(8.79 \%)$ \\
\hline \multicolumn{2}{|l|}{ Ever CT diagnosed $(n=16,417)$} \\
\hline No & $13,835(84.27 \%)$ \\
\hline Yes & $1029(6.27 \%)$ \\
\hline Forgot & $1553(9.46 \%)$ \\
\hline \multicolumn{2}{|c|}{ Current STI-related symptoms ( $n=16,326)$} \\
\hline Yes & $9659(59.16 \%)$ \\
\hline No & 6667 (40.84\%) \\
\hline
\end{tabular}

Having a new sexual partner or multiple sex partners in last 3 months $(n=16,319)$

Yes

$6205(38.02 \%)$
Table 1 Baseline characteristics, knowledge and screening willingness of participants (Continued)

\begin{tabular}{ll}
\hline Variables & Frequency (\%) $^{\mathbf{a}}$ \\
\hline No & $10,114(61.98 \%)$ \\
Knowledge Q1 $(n=16,400)$ & $12,085(73.69 \%)$ \\
Lack of understanding & $4315(26.31 \%)$ \\
$\quad$ Correct understanding & \\
Knowledge Q2 ( $n=16,508)$ & $12,369(74.93 \%)$ \\
Lack of understanding & $4139(25.07 \%)$ \\
Correct understanding & $1856(11.22 \%)$ \\
Routine CT screening willingness $(n=16,546)$ \\
$\quad$ Unwilling & $14,690(88.78 \%)$ \\
Willing &
\end{tabular}

Abbreviations: CT Chlamydia trachomatis, STI Sexually transmitted infections ${ }^{\mathrm{a}} \%$ : Constituent ratio

great range. A regional study in China reported that willingness to undergo STI tests among rural-to-urban migrants was $60.1 \%$ in Beijing and Nanjing [15]. A study in the United States showed that willingness to have STI tests among adolescents was $92.1 \%$ [16]. It was reported that the willingness to have CT tests was $66.3 \%$ in the Netherlands [17]. In addition, most participants in our study $(91.2 \%)$ had not been tested before, suggesting that the expansion of CT screening should be considered in future interventions in those patients without a CT test history. Our findings have proven the data in support of routine CT screening projects, and provide evidence for the promotion and implementation of strategies and recommendations on routine CT screening in China to detect more CT cases.

The present study showed that women were more willing to undergo routine CT screening than men, which is consistent with the findings of a previous study [17]. It was reported that the main motivation of men on CT screening was health reasons, and men who were not willing to have CT screening may have fewer health concerns and underestimate their risk, so they in particular need to obtain CT information [17-19]. However, the result in this study was inconsistent with that in China [15].

The significantly higher willingness to undergo routine CT screening among participants with a higher education level compared to participants with a primary school education level indicated that the population with a low education level had the lowest willingness in this study, which was consistent with past studies [15, 2022]. However, a lower education level is not the only factor. In the current study, participants with a longer length of residency in Shenzhen and higher monthly income were more willing to undergo routine CT screening. A possible reason for these observations is as 
follows: there is a large scale of rural-to-urban migrants in China for numerous economic opportunities, and this population was found to have limited education, shorter length of residency, low income to pay for relatively expensive health services, restricted reproductive health information, and limited access to health services, and to be more vulnerable to STIs [23, 24]. Therefore, rural-tourban migrants, especially migrants with low levels of education, shorter length of residency and lower monthly income should be considered more in health education strategies. This study indicated that the topic of willingness among rural-to-urban migrants should be further considered in future research.

This study also showed that participants with more knowledge about the dangers of CT were more willing to undergo routine CT screening, which was in accordance with findings in other studies [21, 22, 25]. If individuals were informed that chlamydia is a serious condition and common, and could be asymptomatic, they would be more willing to undergo CT screening [25]. Health education interventions could be implemented through doctors, health leaflets, TV ads, magazines, and schools [25].

The current study reported that more than seven-tenths of the participants lacked an understanding of chlamydia infections (Knowledge Q1 $=73.69 \%$; $2=74.93 \%$ ). It is not surprising that many people in the community or going to the clinics are entirely uninformed about urogenital infections of chlamydia (including the danger of infection) in China and in many other countries or areas. Even some health workers working in obstetrics and gynecology do not care about the dangers of CT infections. People sometimes complain about discomfort in the genital tract, but are not aware of any specific infections, including chlamydia. Besides, most of chlamydia infections are asymptomatic. Knowledge is sometimes associated with testing behaviors, but sometimes it is not. For the current survey, participants were told about what the test meant and what the test did for, although we did not pass on intensive education about chlamydia before the questionnaire survey. Therefore, the knowledge and willingness results in our survey reflected real-world situations, and they can be used as background for designing intervention programmes. The impact of intensive or innovative education about chlamydia and its dangers on the willingness to undergo testing or the testing uptake may be a topic for future study.

The current study also found that participants without STI-related symptoms were more willing to undergo routine CT screening, which was inconsistent with a previous systematic review [25]. Symptomatic participants may be affected by moral connotations, stigma, confidentiality, and privacy concerns, so they are unwilling to undergo CT screening. Home-based CT testing, which ensures confidentiality, may be an option to include this population in the screening strategies [26]. Finding a way to normalize and destigmatise chlamydia may also be another strategy to include this population $[25,27]$. Future focus for asymptomatic patients, because their willingness to undergo routine $\mathrm{CT}$ screening was high, should be the acceptability of CT screening to providers if we want to promote routine $\mathrm{CT}$ screening intervention in clinics.

Our study provides evidence and implications for public health interventions on routine CT screening, and suggests that targeted interventions are urgently needed for particular sub-populations, including men, and those with lower education, shorter length of residency, lower monthly income, less awareness about the dangers of CT infection, and with STI-related symptoms.

We found 201 participants, accounting for $1.2 \%$ of the all participants, reported never having been tested and also reported that they had been diagnosed as having a chlamydia infection. There may be at least two possible reasons for this seemingly contradictory observation. First, syndromic diagnosis is still used by some doctors to simply make a patient diagnosed as having a chlamydia infection. Second, recall bias on testing or diagnosis may occur in some patients.

Several limitations exist in the present study. First, the representativeness of this study should be considered by using the convenience-sampling method to include participants. The first 15 eligible patients per day in each study site may be younger, as patients have to make an online appointment (mostly through an app in the smartphone) for an early visit. However, with the inclusion criteria of participants' age (between 18 and 49 years) and a relatively large sample size (16,546 participants) across 6 of 10 city districts and 22 hospitals, the representativeness of our study could be reliable. The generalizability of this study should also be considered by using the convenience-sampling method, which recruited the first 15 eligible patients per day in each study site. In Shenzhen, participants who make an online appointment have priority to see a doctor, which may be different from other cities or countries with limited resources. Second, social desirability bias related to sexual and health behaviors may exist in the questionnaire survey. Third, as we did not collect data on those patients who rejected to participate in the survey, it is impossible to know the comparability of this group of patients with those who participated in the survey, resulting in the possibility of selection bias. Fourth, we did not provide information for participants about what type of annual CT testing they would take. This study provided a basic understanding of the willingness to undergo routine $\mathrm{CT}$ screening among hospital-based patients in China, and further research on more specific types of routine CT 
Table 2 Multivariable logistic regression analysis of factors associated with willingness to undergo routine CT screening

\begin{tabular}{|c|c|c|c|c|}
\hline Variables & $\begin{array}{l}\text { Crude OR } \\
(95 \% \mathrm{Cl})\end{array}$ & $P$ Values & $\begin{array}{l}\text { Adjusted OR } \\
(95 \% \mathrm{Cl})\end{array}$ & $P$ Values \\
\hline \multicolumn{5}{|l|}{ Gender } \\
\hline Men & Reference & & Reference & \\
\hline Women & $1.42(1.29,1.57)$ & $<0.001^{* *}$ & $1.53(1.34,1.75)$ & $<0.001^{* *}$ \\
\hline \multicolumn{5}{|l|}{ Age groups } \\
\hline$\leq 24$ & Reference & & Reference & \\
\hline$>24$ & $1.23(1.08,1.40)$ & $0.002^{*}$ & $1.11(0.87,1.40)$ & 0.401 \\
\hline \multicolumn{5}{|l|}{ Marital status } \\
\hline Single/Divorced/Widowed & Reference & & Reference & \\
\hline Married & $1.18(1.06,1.32)$ & $0.002^{*}$ & $1.10(0.89,1.35)$ & 0.368 \\
\hline \multicolumn{5}{|l|}{ Living separate and apart } \\
\hline Yes & Reference & & Reference & \\
\hline No & $1.16(1.00,1.35)$ & 0.057 & $0.97(0.81,1.15)$ & 0.732 \\
\hline \multicolumn{5}{|l|}{ Shenzhen Hukou } \\
\hline No & Reference & & Reference & \\
\hline Yes & $1.36(1.21,1.52)$ & $<0.001^{* *}$ & $1.12(0.96,1.31)$ & 0.152 \\
\hline \multicolumn{5}{|l|}{ Length of residency } \\
\hline$<1$ year & Reference & & Reference & \\
\hline$\geq 1$ year & $1.81(1.60,2.06)$ & $<0.001^{* *}$ & $1.64(1.37,1.95)$ & $<0.001^{* *}$ \\
\hline \multicolumn{5}{|l|}{ Education level } \\
\hline Primary school & Reference & & Reference & \\
\hline Any secondary $\backslash$ & $2.89(2.37,3.52)$ & $<0.001^{* *}$ & $2.46(1.92,3.15)$ & $<0.001^{* *}$ \\
\hline \multicolumn{5}{|l|}{ Monthly income (RMB) } \\
\hline 0-4999 & Reference & & Reference & \\
\hline $5000-9999$ & $1.09(0.97,1.21)$ & 0.142 & $0.96(0.83,1.11)$ & 0.566 \\
\hline $10,000-$ & $1.44(1.24,1.68)$ & $<0.001^{* *}$ & $1.24(1.01,1.51)$ & $0.036^{*}$ \\
\hline \multicolumn{5}{|l|}{ Health insurance } \\
\hline No & Reference & & Reference & \\
\hline Yes & $1.14(1.03,1.26)$ & $0.012^{*}$ & $0.92(0.80,1.05)$ & 0.214 \\
\hline \multicolumn{5}{|l|}{ Sexual orientation } \\
\hline Homosexuality/bisexuality & Reference & & Reference & \\
\hline Heterosexuality & $0.69(0.45,1.05)$ & 0.081 & $0.75(0.42,1.34)$ & 0.337 \\
\hline \multicolumn{5}{|l|}{ Ever $C T$ tested } \\
\hline No & Reference & & Reference & \\
\hline Yes & $1.84(1.48,2.28)$ & $<0.001^{* *}$ & $1.16(0.85,1.57)$ & 0.355 \\
\hline \multicolumn{5}{|l|}{ Ever $\mathrm{CT}$ diagnosed } \\
\hline No & Reference & & Reference & \\
\hline Yes & $2.34(1.78,3.07)$ & $<0.001^{* *}$ & $1.44(0.97,2.14)$ & 0.068 \\
\hline Forgot & $1.61(1.33,1.95)$ & $<0.001^{* *}$ & $1.42(1.12,1.79)$ & $0.004^{*}$ \\
\hline \multicolumn{5}{|l|}{ Current STI-related symptoms } \\
\hline Yes & Reference & & Reference & \\
\hline No & $1.18(1.07,1.31)$ & $0.001^{*}$ & $1.24(1.10,1.41)$ & $0.001^{*}$ \\
\hline
\end{tabular}

Having a new sexual partner or multiple sex partners in last 3 months 
Table 2 Multivariable logistic regression analysis of factors associated with willingness to undergo routine CT screening (Continued)

\begin{tabular}{|c|c|c|c|c|}
\hline Variables & $\begin{array}{l}\text { Crude OR } \\
(95 \% \mathrm{Cl})\end{array}$ & $P$ Values & $\begin{array}{l}\text { Adjusted OR } \\
(95 \% \mathrm{Cl})\end{array}$ & $P$ Values \\
\hline No & $0.98(0.88,1.08)$ & 0.639 & & \\
\hline \multicolumn{5}{|l|}{ Knowledge Q1 } \\
\hline Lack of understanding & Reference & & Reference & \\
\hline Correct understanding & $1.43(1.27,1.61)$ & $<0.001^{* *}$ & $1.01(0.85,1.21)$ & 0.902 \\
\hline \multicolumn{5}{|l|}{ Knowledge Q2 } \\
\hline Lack of understanding & Reference & & Reference & \\
\hline Correct understanding & $1.85(1.63,2.11)$ & $<0.001^{* *}$ & $1.68(1.39,2.03)$ & $<0.001^{* *}$ \\
\hline
\end{tabular}

Abbreviations: Cl Confidence interval, CT Chlamydia trachomatis, OR Odds ratio, STI Sexually transmitted infections ${ }^{*} P<0.05,{ }^{* *} P<0.001$

screening (e.g., free CT testing) is needed. Lastly, this study focused on willingness, and not behavioral intentions or actual behavior (e.g., acceptability of CT screening). Future studies are needed to find out how to translate the high willingness of routine CT screening to actual acceptability of CT screening. The associated factors that we found (e.g., gender, symptom status, awareness of the dangers of CT infection) may indicate an initial point for developing promising intervention strategies in this area.

\section{Conclusion}

In summary, this study reported a high willingness to undergo routine CT screening among hospital-based patients in Shenzhen, which indicated that the CT screening programme should be scaled up in the above setting. Our findings suggested that gender, education level, length of residency, monthly income, CT knowledge,

Table 3 The VIF value of all independent variables

\begin{tabular}{ll}
\hline Variables & VIF \\
\hline Gender & 1.131 \\
Age groups & 1.219 \\
Marital status & 1.205 \\
Living separate and apart & 1.037 \\
Shenzhen Hukou & 1.224 \\
Length of residency & 1.123 \\
Education level & 1.075 \\
Monthly income (RMB) & 1.250 \\
Health insurance & 1.156 \\
Sexual orientation & 1.004 \\
Ever CT tested & 1.293 \\
Ever CT diagnosed & 1.210 \\
Current STI-related symptoms & 1.033 \\
Knowledge Q1 & 1.508 \\
Knowledge Q2 & 1.497 \\
\hline Abbreviations: CT Chlamydia trachomatis, STI Sexually transmitted infections, \\
VIF Variance inflation factor
\end{tabular}

and STI-related symptoms are associated factors of willingness to undergo routine CT screening.

\section{Supplementary Information}

The online version contains supplementary material available at https://doi. org/10.1186/s12889-020-09828-6.

Additional file 1. The questionnaire from the baseline study in the Shenzhen Gonorrhea and Chlamydia Intervention Programme; This file provides details of the questionnaire from the baseline study in the Shenzhen Gonorrhea and Chlamydia Intervention Programme.

\section{Abbreviations}

AOR: Adjusted odds ratios; Cl: Confidence interval; CT: Chlamydia trachomatis; NCSP: National Chlamydia Screening Programme; PID: Pelvic inflammatory disease; SD: Standard deviation; SGCIP: Shenzhen Gonorrhea and Chlamydia Intervention Programme; SPSS: Statistical Package for Social Sciences; STI: Sexually transmitted infection; VIF: Variance inflation factor; WHO: World Health Organization

\section{Acknowledgements}

We are indebted to all participants in this study for their cooperation. We thank staffs at all participated hospitals, Center for chronic disease control and Center for disease control and prevention.

\section{Authors' contributions}

RW, YC and XC conceived and designed the study. FH, CZ, and LW supervised the data collection. YC, XC, RW, FH, CZ, and LW performed the research. RW, YC analysed and interpreted the results and were the major contributors in writing the manuscript. All authors read and approved the final manuscript.

\section{Funding}

This study was supported by Sanming project of Medicine in Shenzhen (No.SZSM201611077). The funder had no role in study design, data collection and analysis, decision to publish, or preparation of the manuscript.

\section{Availability of data and materials}

The datasets used and/or analysed during the current study are available from the corresponding author on reasonable request. Data request should be submitted to Dr. Yumao Cai (64165469@qq.com) who will review the data request with Ethical Review Committee of Shenzhen Center for Chronic Disease Control for approval.

\section{Ethics approval and consent to participate}

This study was approved by Ethical Review Committee of the Shenzhen Center for Chronic Disease Control (Approval No.20180206). Written informed consent was obtained from each participant. 


\section{Consent for publication}

Not applicable.

\section{Competing interests}

The authors declare that they have no competing interests.

\section{Author details}

'Department of STD Control and Prevention, Shenzhen Center for Chronic Disease Control, No. 2021, Buxin Road, Luohu District, Shenzhen City 518020, Guangdong Province, China. ${ }^{2}$ Peking Union Medical College Institute of Dermatology, Chinese Academy of Medical Science and Peking Union Medical College, Nanjing 210042, China. ${ }^{3}$ National Center for Sexually Transmitted Disease Control, Nanjing, China.

Received: 8 January 2020 Accepted: 4 November 2020

Published online: 16 November 2020

\section{References}

1. Newman L, Rowley J, Vander Hoorn S, Wijesooriya NS, Unemo M, Low N, et al. Global estimates of the prevalence and incidence of four curable sexually transmitted infections in 2012 based on systematic review and global reporting. PLoS One. 2015;10(12):e0143304.

2. Westrom L, Joesoef R, Reynolds G, Hagdu A, Thompson SE. Pelvic inflammatory disease and fertility. A cohort study of 1,844 women with laparoscopically verified disease and 657 control women with normal laparoscopic results. Sex Transm Dis. 1992;19(4):185-92.

3. Haggerty CL, Gottlieb SL, Taylor BD, Low N, Xu F, Ness RB. Risk of sequelae after chlamydia trachomatis genital infection in women. J Infect Dis. 2010; 201(Suppl 2):S134-55.

4. Taylor BD, Haggerty CL. Management of Chlamydia trachomatis genital tract infection: screening and treatment challenges. Infect Drug Resist. 2011; 4:19-29.

5. Agarwal A, Rana M, Qiu E, AlBunni H, Bui AD, Henkel R. Role of oxidative stress, infection and inflammation in male infertility. Andrologia. 2018;50(11): e13126.

6. Peipert JF. Clinical practice. Genital chlamydial infections. N Engl J Med. 2003:349(25):2424-30.

7. Lanjouw E, Ouburg S, de Vries HJ, Stary A, Radcliffe K, Unemo M. 2015 European guideline on the management of chlamydia trachomatis infections. Int J STD AIDS. 2016:27(5):333-48.

8. Workowski KA, Berman SM. Centers for Disease Control and Prevention sexually transmitted diseases treatment quidelines; 2007.

9. Low N, Cassell JA, Spencer B, Bender N, Hilber AM, van Bergen J, et al. Chlamydia control activities in Europe: cross-sectional survey. Eur J Pub Health. 2012;22(4):556-61.

10. Macintosh M, McKee M. The English National Chlamydia Screening Programme: where next? Public Health. 2013;127(7):681-3.

11. Yan RL, Ye YF, Fan QY, Huang YH, Wen GC, Li LM, et al. Chlamydia trachomatis infection among patients attending sexual and reproductive health clinics: a cross-sectional study in Bao'an district, Shenzhen, China. PloS One. 2019;14(2):e0212292.

12. Marrazzo JM, Celum CL, Hillis SD, Fine D, DeLisle S, Handsfield HH. Performance and cost-effectiveness of selective screening criteria for chlamydia trachomatis infection in women. Implications for a national chlamydia control strategy. Sex Transm Dis. 1997;24(3):131-41.

13. Shannon CL, Bristow C, Hoff N, Wynn A, Nguyen M, Medina-Marino A, et al. Acceptability and feasibility of rapid chlamydial, Gonococcal, and Trichomonal screening and treatment in pregnant women in 6 Low- to middle-income countries. Sex Transm Dis. 2018:45(10):673-6.

14. Song Q, Smith JP. Hukou system, mechanisms, and health stratification across the life course in rural and urban China. Health Place. 2019;58:102150.

15. Wang B, Li X, Stanton B, McGuire J. Correlates of HIV/STD testing and willingness to test among rural-to-urban migrants in China. AIDS Behav. 2010;14(4):891-903.

16. Ford CA, Best D, Miller WC. The pediatric forum: confidentiality and adolescents' willingness to consent to sexually transmitted disease testing Arch Pediatr Adolesc Med. 2001;155(9):1072-3

17. Greenland KE, Op de Coul EL, van Bergen JE, Brouwers EE, Fennema HJ, Gotz HM, et al. Acceptability of the internet-based chlamydia screening implementation in the Netherlands and insights into nonresponse. Sex Transm Dis. 2011;38(6):467-74.
18. Hart GJ, Duncan B, Fenton KA. Chlamydia screening and sexual health. Sex Transm Infect. 2002:78(6):396-7.

19. Lorimer K, Reid ME, Hart GJ. Willingness of young men and women to be tested for chlamydia trachomatis in three non-medical settings in Glasgow, UK. J Fam Plann Reprod Health Care. 2009;35(1):21-6.

20. Xun H, Kang D, Huang T, Qian Y, Li X, Wilson EC, et al. Factors associated with willingness to accept oral fluid HIV rapid testing among most-at-risk populations in China. PLoS One. 2013:8(11):e80594.

21. Gage AJ, Ali D. Factors associated with self-reported HIV testing among men in Uganda. AIDS Care. 2005;17(2):153-65.

22. Lee K, Cheung WT, Kwong VS, Wan WY, Lee SS. Access to appropriate information on HIV is important in maximizing the acceptance of the antenatal HIV antibody test. AIDS Care. 2005;17(2):141-52.

23. He N. Sociodemographic characteristics, sexual behavior, and HIV risks of rural-to-urban migrants in China. Biosci Trends. 2007:1(2):72-80.

24. Zhang X, Zhang T, Pei J, Liu Y, Li X, Medrano-Gracia P. Time series Modelling of syphilis incidence in China from 2005 to 2012. PLoS One. 2016;11(2):e0149401

25. Pavlin NL, Gunn JM, Parker R, Fairley CK, Hocking J. Implementing chlamydia screening: what do women think? A systematic review of the literature. BMC Public Health. 2006;6:221.

26. McRee AL, Esber A, Reiter PL. Acceptability of home-based chlamydia and gonorrhea testing among a national sample of sexual minority young adults. Perspect Sex Reprod Health. 2015;47(1):3-10.

27. Pavlin NL, Parker R, Fairley CK, Gunn JM, Hocking J. Take the sex out of ST screening! Views of young women on implementing chlamydia screening in General Practice. BMC Infect Dis. 2008;8:62.

\section{Publisher's Note}

Springer Nature remains neutral with regard to jurisdictional claims in published maps and institutional affiliations.
Ready to submit your research? Choose BMC and benefit from:

- fast, convenient online submission

- thorough peer review by experienced researchers in your field

- rapid publication on acceptance

- support for research data, including large and complex data types

- gold Open Access which fosters wider collaboration and increased citations

- maximum visibility for your research: over $100 \mathrm{M}$ website views per year

At BMC, research is always in progress.

Learn more biomedcentral.com/submissions 